\title{
On the Variation of Geomagnetic H-Component during Solar Quiet Days
}

\author{
Ernest Benjamin Ikechukwu Ugwu and Christopher Ekene Okeke
}

\section{ABSTRACT}

The hourly variation of the H-component of the geometric field from two equatorial electrojet stations, Huancayo and Addis Ababa, and one nonequatorial electrojet station, Alibag, were studied to find out the trend of solar quiet variation of $\mathrm{H}$ for the year 2008 . The $\mathrm{dH}$ amplitudes of the electrojet stations showed enhancement in $H$, while there was no enhancement in the non-electrojet station which was located far away from the dip equator. The day-to-day monthly diurnal variation was, however, observed in all the three stations. Also, at nighttime, the $\mathrm{dH}$ amplitudes of all the stations were non-zero which we attributed to non-ionospheric current sources like the magnetosphere since at night there was no solar radiations. For seasonal variations, an Equinoctial maximum, J-Solstitial maximum, and S-Solstitial maximum were observed in the equatorial stations while the non-equatorial station recorded an equinoctial minimum, J-solstitial minimum and D-Solstitial minimum.

Keywords: Dip equator, equatorial electrojet, geomagnetic field, Hcomponent, solar flare.

\section{INTRODUCTION}

The variation of geomagnetic H-component in the Earth's magnetic field could be attributed to the regular variations in the geomagnetic field due to the Earth's rotation on its axis and the orbital movement around the sun as well as the orbital motion of the moon. The diurnal variations also called solar daily variations are prominent of the regular variations. The causes of this diurnal variation of the geomagnetic horizontal component, $\mathrm{H}$ can be traced to the electric currents flowing in the E-layer during the daytime in the ionosphere in the dip equator and partly due to currents in the Earth's crust caused by electromagnetic induction.

There are a number of current systems during geomagnetically quiet time periods which forms part of the solar quiet, Sq current system which include the equatorial electrojet, field-aligned currents and low-latitude and mid latitude currents flowing in the E-region of the ionosphere. The Sq current system is characterized by its seasonal and solar cycle variations and because of differences in conductivity and winds, $\mathrm{Sq}$ current system is not hemispherically symmetric. The feature exhibits a marked seasonal variation with current intensity in the summer hemisphere being greater that the current intensity in the winter hemisphere. In any case, the maximum total currents do occur around equinox [1]-[3].

Diurnal variations in geomagnetic field under quiet and/or disturbed days seen as enhancement in the $\mathrm{H}$-component with peaks around local noon have been variously reported [4]-[8]. Abbas et al. [9] reported that $\mathrm{Sq}(\mathrm{H})$ variation exists throughout the year with a maximum during the June solstice in Ancon and Dadao while Ilorin, Nigeria has maximum seasonal variation in Equinox. The equatorial electrojet system has East-West component [9] with the east being stronger than the West as well as a North-South component.

\section{SOURCES OF DATA}

Two equatorial electrojet stations, Addis Ababa and Huancoyo and one non-equatorial electrojet station, Alibag were used for the study. The set of geomagnetic data consists of hourly values of horizontal geomagnetic, Hcomponent obtained from the World Data centre, Kyoto Japan (http//.www.wdc.kyoto.com) for the year 2008).

\begin{tabular}{cccccc}
\multicolumn{6}{c}{ TABLE I: THE GEOGRAPHIC AND GEOMAGNETIC COORDINATES OF THE STATIONS USED } \\
\hline Stations & Codes & $\begin{array}{c}\text { Geographic } \\
\text { latitude }\left({ }^{0}\right)\end{array}$ & $\begin{array}{c}\text { Geographic } \\
\text { Longitude }\left({ }^{0}\right)\end{array}$ & $\begin{array}{c}\text { Geomagnetic } \\
\text { Latitude }\left({ }^{0}\right)\end{array}$ & $\begin{array}{c}\text { Geomagnetic } \\
\text { Longitude }\left({ }^{0}\right)\end{array}$ \\
\hline Adiss Ababa & AAB & 9.04 & 38.77 & 0.18 & 110.23 \\
Alibag & ALI & 18.64 & 72.87 & 10.37 & 146.55 \\
Huancayo & HUA & -12.06 & -75.20 & 1.40 & 356.12 \\
\hline
\end{tabular}




\section{THEORY AND METHOD OF THE DATA ANALYSIS}

The set of geomagnetic data consisting of hourly values of the horizontal component, $\mathrm{H}$, recorded at two equatorial electrojet (EEJ) stations along the dip equator and a nonequatorial electrojet observatory as shown in Table 1 were downloaded. The two EEJ stations are Addis Ababa and Huancayo while Alibag is the non-equatorial EEJ station. Five international quiet days (IQDs) were selected based on the magnetic activity index, Kp values i.e., the five quietest days of each month were picked for the year 2008. This is to ensure that only the quiet conditions of each month were examined.

The idea of local time (LT) was used throughout the analysis. The variation baseline was obtained from the two hours flanking local midnight, that is $23.00 \mathrm{hrs} \mathrm{LT}$ and 01:00 hr LT. The daily baseline values (Ho) for the geomagnetic element $\mathrm{H}$ are the mean values of the hourly values at these two hours. The value of $\mathrm{H}$ is given as:

$$
H=\sqrt{(X)^{2}+(Y)^{2}}
$$

where $x$ and $y$ are the Cartesian frame of the coordinates the form in which the data were given.

The daily baseline values were calculated from Equation 2 below:

$$
H_{o}=\left(H_{23}+H_{01}\right) / 2
$$

where $\mathrm{H}_{23}$ and $\mathrm{H}_{01}$ represent the values of the geomagnetic element $\mathrm{H}$ at 23:00 hrs and 01:00 hrs respectively.

The midnight values $\mathrm{H}_{0}$, were subtracted from hourly values $H_{t}$, to get the hourly departures $H_{i}$ from the midnight for a particular ith day, as shown in (3) below:

$$
H_{i}=H_{t}-H_{0}
$$

where $\mathrm{i}=1$ to 365 days, $\mathrm{t}=$ 01:00 to 23:00 hours LT; Ht is the hourly values of geomagnetic element $\mathrm{H}$ and $\mathrm{Hi}$ gives a measure of the hourly amplitude of the variation of $\mathrm{H}$.

Studying the day-to-day variabilities in the horizontal component was only possible for the consecutive International Quiet Days (IQDs). The variability of the hourly amplitude for a fixed hour say (t) from on international quiet day (i) to the next succeeding quiet day $(i+1)$ are given in (4):

$$
H_{d d}=H_{t(i+1)-} H_{t i}
$$

where $\mathrm{H}_{\mathrm{dd}}=$ hourly amplitude for a fixed hour, $\mathrm{H}(\mathrm{i}+1)=$ hourly amplitude for the succeeding day, $\mathrm{H}_{\mathrm{ti}}=$ the $\mathrm{H}$ value for a fixed hour $t$.

For the study of seasonal variation, the months of the year were classified according to Lloyd's seasons [10], into D season (January, February, November and December), E Season (March, April, September and October); and J season (May, June, July and August). The seasonal values were then estimated by averaging the values for all the months in a particular season. These averaged values were then plotted to show the seasonal variations in $\mathrm{S}_{\mathrm{q}}(\mathrm{H})$.

\section{RESULTS AND DisCUSSIONS}
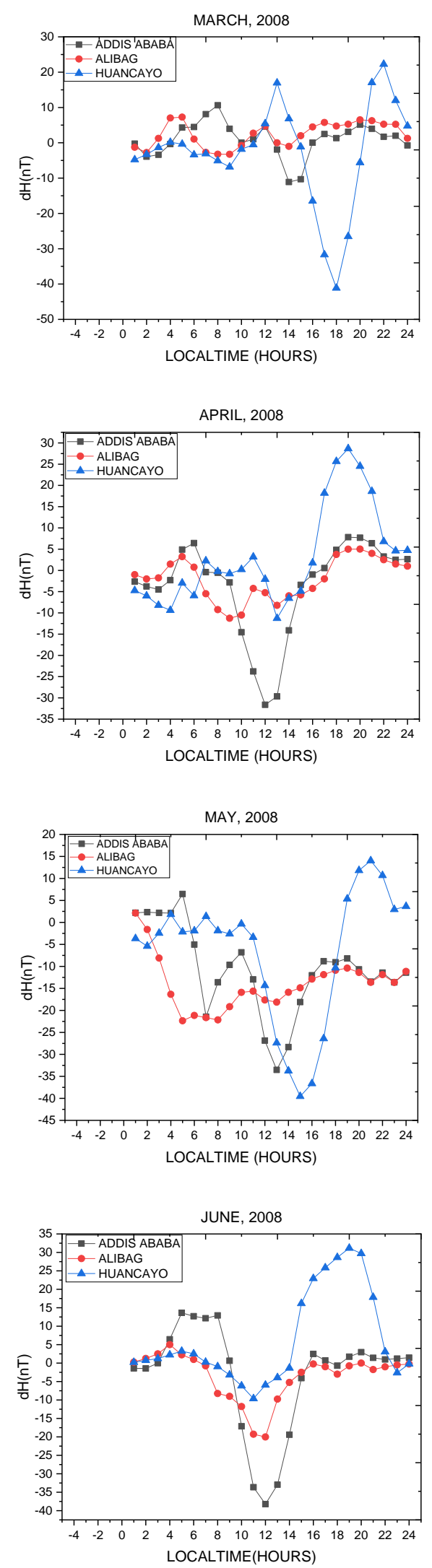

Fig. 1. Graphs of the Day-To-Day Variability of the Monthly Variation of the Geomagnetic Horizontal Component, H, for January, February, March, April, May, and June for the Year 2008. 

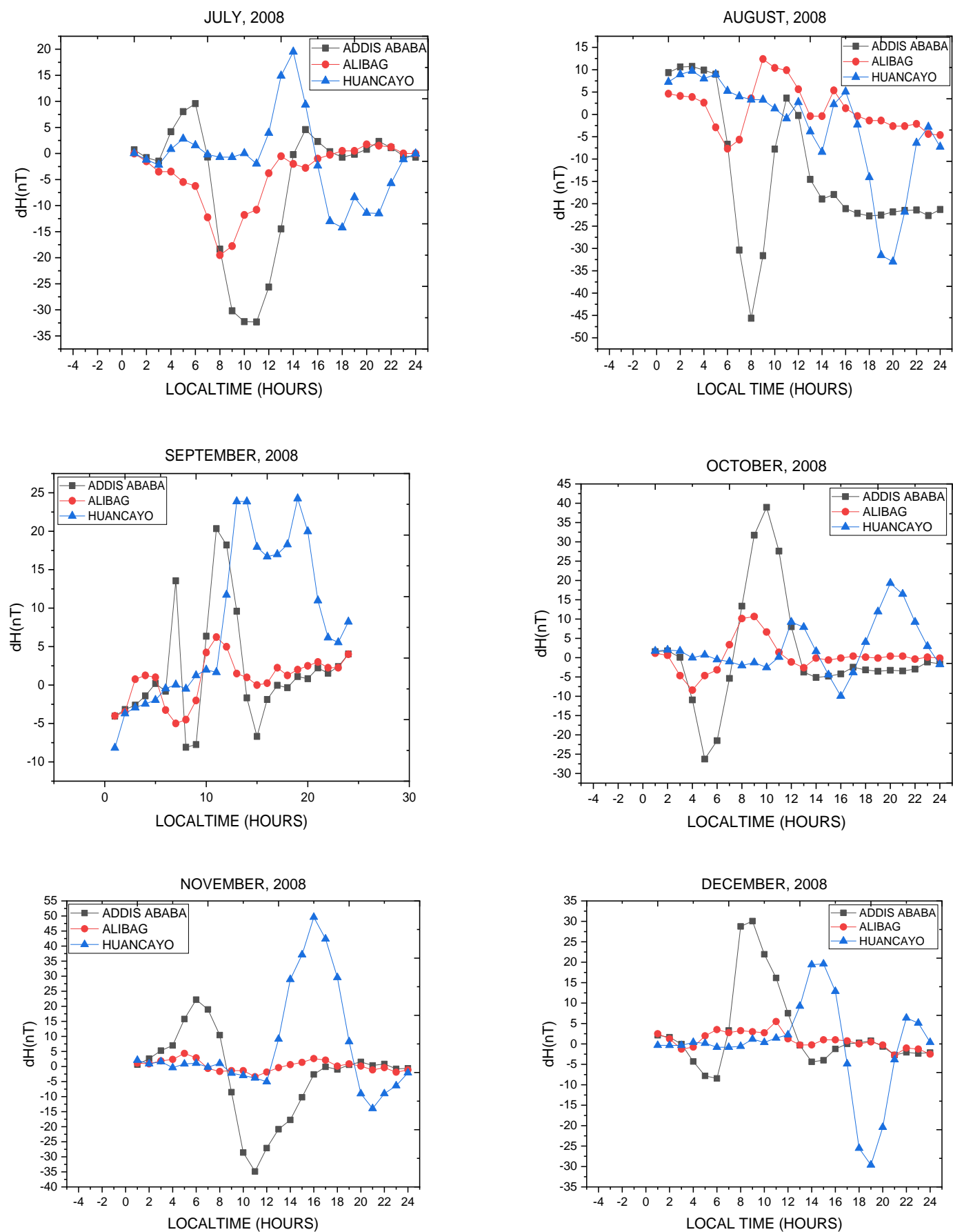

Fig. 2. Graphs of the Day-To-Day Variability of the Monthly Variation of the Geomagnetic Horizontal Component, H, for July, August, September, October, November and December for the Year 2008
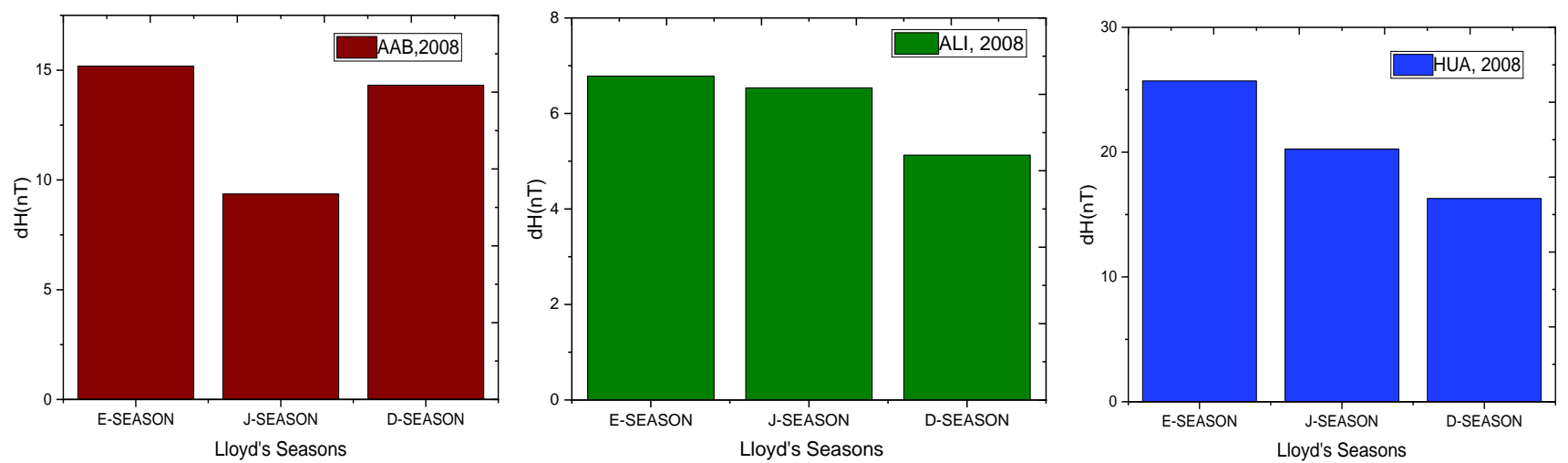

Fig. 3. Graphs of the Seasonal Variation of $\mathrm{H}$ in all three Stations for the Year 2008. 
Fig. 1 and 2 show the day-to-day monthly diurnal variations obtained from the sum of hourly means values of horizontal, $\mathrm{H}$ component of the geomagnetic values for the five international quiet days for each month from January to December for the three stations studied i.e., Addis Ababa, Huancayo and Alibag respectively for the year 2008. While Addis Ababa and Huancayo are equatorial electrojet stations, Alibag is a non-equatorial electrojet station. Fig. 3 show the seasonal variation of $\mathrm{Sq}(\mathrm{H})$ which was obtained by summing the averages of the $\mathrm{dH}$ amplitudes for each month using Lloyd's season given by: the E-season (March, April, September and October); the J- season (May, June, July and August) and D-season (January, February, November and December) in all the three stations.

The day-to-day monthly diurnal variations in $\mathrm{H}$ component in the two equatorial electrojet stations, Addis Ababa and Huancayo had similar patterns: it increased regularly from dawn and gradually reduced from dusk, but it was always non-zero at night. Alibag, a non-EEJ station, had a different pattern for the geomagnetic $\mathrm{H}$ component variation. Also, while Alibag showed little or no enhancement during the daytime, both Addis Ababa and Huancayo showed enhancement during the daytime. However, different peak times were recorded during the day for all the stations. For Addis Ababa, the peak time occurred mostly between 07:00 LT and 09:00 LT while Huancayo showed peak mostly around local noon between 15:00 LT and 17:00 LT. Alibag peak time was mostly between 06:00 LT and 07:00 LT. Nighttime variations in $\mathrm{Sq}(\mathrm{H})$ were also observed with negative amplitude in $\mathrm{dH}$ but the $\mathrm{dH}$ amplitudes were never zero.

The enhancements in $\mathrm{dH}$ amplitude in the EEJ stations is attributed to the EEJ current which is a narrow belt of intense electric current in the ionosphere confined to the dip latitude of about $\pm 3^{\circ}$ around the dip equator - which is usually indicated in the magnetogram as enhancements of solar quiet variation of the horizontal component of the magnetic field, $\mathrm{Sq}(\mathrm{H})$. Hence, Addis Ababa and Huancayo which have dip latitude of $0.57^{\circ}$ and $0.6^{\circ}$ respectively are within this EEJ current belt while Alibag with a latitude of $10^{\circ}$ is located far away from the EEJ current belt making it a non-EEJ station and hence no enhancement. The nighttime consistent variation but with non-zero $\mathrm{dH}$ amplitude, though negative $\mathrm{dH}$ amplitude in the geomagnetic horizontal $\mathrm{H}$ component at mid latitudes was attributed to distant magnetospheric sources [11].

It was also observed that generally during the Equinox months of March and September, the diurnal variation was higher than those recorded during the solstice months of June and December. This is traced to increased solar activity as the sun shines directly above the equator during equinoctial months thereby causing more ionization within the dip equator. This is in agreement with the results of Chapman and Rajarao [12].

For Addis Ababa, the equinoctial maximum of $\mathrm{Sq}(\mathrm{H})$ during E-season was 15.2nT, a D-solstitial maximum of $14.3 \mathrm{nT}$ and a J-solstitial maximum of 9.4nT. Huancayo showed a seasonal variation in $\mathrm{Sq}(\mathrm{H})$ with an equinoctial maximum of $25.7 \mathrm{nT}$, a J-solstitial maximum of $20.3 \mathrm{nT}$ and a D-solstitial maximum of $16.3 \mathrm{nT}$. These enhancements are because the two stations are EEJ stations with EEJ current flowing within their belts. Also, the E-season (equinoctial seasons) are greater than the solstitial seasons because of increased solar activity resulting to increased current due to increased solar ionization at the dip equator. Alibag, a non EEJ station had the least $\mathrm{dH}$ seasonal amplitudes with equinoctial maximum of $6.5 \mathrm{nT}$, a D-solstitial maximum of only $5.1 \mathrm{nT}$ and a J-solstitial maximum of $6.5 \mathrm{nT}$, hence there is no enhancement because Alibag is outside the EEJ current belt.

\section{CONCLUSION}

From our study the solar quiet day variation of the horizontal geomagnetic field, $\mathrm{Sq}(\mathrm{H})$ can be seen as a dusk to dawn phenomenon. The $\mathrm{dH}$ amplitude increases from dawn and decreases from dusk but will always be non-zero even though negative values of $\mathrm{dh}$ amplitudes were recorded at night. These negative values were attributed to nonionospheric distant sources of current e.g., the magnetospheric current.

The day-to-day monthly diurnal variation of $\mathrm{Sq}(\mathrm{H})$ followed a pattern for the equatorial electrojet stations, Addis Ababa and Huancayo, with enhancement around local noon while non-EEJ station of Alibag showed no enhancement. The enhancements observed in the EEJ stations were attributed to EEJ current belt which flows between $\pm 3^{0}$ of the dip equator. Alibag generally had low $\mathrm{dH}$ amplitudes because it is located far from the dip equatorial latitude i.e., outside the 30 dip equator belt and as such the EEJ current had no effect in the $\mathrm{dH}$ amplitude which is seen as no enhancement.

The seasonal variations in the three stations generally showed that the sum of the averages of $\mathrm{dH}$ amplitude for the months recorded during the equinoctial season (E seasons) of March, April, September, and October were greater than those recorded in the solstitial J-season (May, June July and August) and solstitial D-season (January, February, November and December). During equinox there is increased solar activity leading to increased ionization with increased ionospheric current within the equatorial latitudes where the sun now shines directly on. This is seen in the equinoctial maximum observed in Addis Ababa and Huancayo and solstitial minimum observed in Alibag, a no EEJ station.

\section{REFERENCES}

[1] Matsushita, S. and Maeda, H. (1965), The geomagnetic solar quiet daily variation field during the International Geophysics Year, Journal of geophysics Resolution, 70, 2535-2558.

[2] Matsushita, S. and Campbell, W.H. (1967), Physics of geomagnetic phenomena, Journal of Royal Meteorology Society, 94, 401.

[3] Takeda, M. and Iyemori, T. (2003), Relationship between electric field and currents in the ionosphere and the geomagnetic sq field, Journal of Geophysics Resolution, 108, 1183

[4] Akpaneno, A.F. and Adimula, I.A. (2005), Variability of Hcomponent of the geomagnetic field from some equatorial electrojet stations, The international Journal of Sun and Geosphere, 10, 65-65.

[5] Ridwan, O.A. (2015), Analytical interpretation of geomagnetic field anomaly along the dip equator, International Journal of Humanities, Arts, Medicines and Sciences, 3, 29-44.

[6] Abbas M., Joshua, B., Bonde, M., and Gwani, M. (2014) Longitudinal and seasonal variation along the magnetic equator using MAGDAS data, International Journal of Marine, Atmospheric \& Earth Sciences, 1, 8-16. 
[7] Obiekezie, T.N. and Obadazie, S.C. (2013), The variability of H component of geomagnetic field at the African sector, Journal of Physical Review and Research International, 3, 154-160.

[8] Okeke, F.N. and Hamano, Y. (2000), Daily variations of geomagnetic $\mathrm{H}, \mathrm{D}$ and Z-fields at the equatorial latitudes, Journal of Earth Planet Space, 52, 237-243.

[9] Abbas M. and Salihu, M. (2014), Variability strength of the equatorial electrojet over Africa during low solar activity, International Journal of Marine, Atmospheric \& Earth Sciences, 2, 28-40.

[10] Egeland, A., Holter, O., Omholt, A (1973), in Eleman, F. (1973), The geomagnetic field in cosmical geophysics ed., Scandinavian University Books, Oslo, 45-62.

[11] Rabiu, A.B. (1996), Nighttime geomagnetic variations at middle latitudes, Nigerian Journal of Physics, 8, 35-37.

[12] Chapman, S. and Rajarao, K.O. (1965), The $\mathrm{H}$ and $\mathrm{Z}$ variations along and near the equatorial electrojet in India, Africa and Pacific Journal of Atmosphere and Terrestrial Physics, 27, 559-581.

[13] Campbell, W.H. (1967), The regular geomagnetic field variations during quiet solar conditions, Journal of Geomatics Engineering Research, 3, 386-460. 